\title{
Parental appearance teasing in adolescence and associations with eating problems: a systematic review
}

\author{
Lucy M. Dahill ${ }^{1 *}$, Stephen Touyz ${ }^{2}$, Natalie M. V. Morrison ${ }^{1,3}$ and Phillipa Hay ${ }^{1,3}$
}

\begin{abstract}
Background: The adolescent years see significant physical and emotional development that lay foundations for patterns of behaviour that can continue into adult life, including the shaping of eating behaviours. Given parents are key socio-environmental drivers and influencers of adolescent behaviours around physical health and wellbeing, it is critical to consider if specific forms of parental communication are potentially contributing to the associated emotional difficulties experienced in the adolescent years. The aim of this research was to systematically review the myriad of literature pertaining to the prevalence of parental weight or appearance-based teasing and adolescent eating problems to examine how the scientific and clinical community currently understands the relationship between these domains.

Methods: A systematic search of the literature, using the SCOPUS, APA PsycINFO, Medline, CINAHL databases, reference lists and Google Scholar, was undertaken to identify relevant literature for parental teasing and problem eating in adolescents aged 10-19years, published between January 1980 to October 2020, in English or French.

Results: Six studies met criteria for inclusion, all were cross-sectional studies and two included additional prospective data. Although parents were not the most common perpetrators of teasing, often subsidiary to that of peers and siblings, the influence and impact of parental teasing remained significant, and in some cases, appeared to interact with sibling-based teasing. This teasing was associated with problem eating behaviours for adolescents.

Conclusions: There is evidence in the literature to suggest the existence of an association between 'eating problems' amongst adolescents and exposure to parental appearance or weight teasing. Parents are unlikely to be aware of the perception or impact of the words they use or the wider influence these words may have. Future research should employ representative longitudinal designs to develop a greater understanding of the relationships between parental communications around their adolescent's appearance or weight and how that communication is perceived by adolescents within complex family processes.
\end{abstract}

Trial registration: PROSPERO 2018 CRD42018109623. Prospectively registered 15th October 2018.

Keywords: Adolescents, Teasing, Body image, Eating problems, Eating disorder, Parent child communication, Appearance teasing, Weight teasing, Shape teasing, Family processes

\footnotetext{
*Correspondence: I.dahill@westernsydney.edu.au; lucy@lucydahill.com

${ }^{1}$ Translational Health Research Institute, Western Sydney University, Locked Bag 1797, Penrith, NSW 2751, Australia

Full list of author information is available at the end of the article
} 


\section{Background}

According to the World Health Organisation (WHO), adolescence, defined between 10 and 19 years of age, [1] is a time of rapid physical, emotional and cognitive development which creates a unique population requiring age specific attention to development and health [2]. It is during this period of development that foundations are set for patterns of behaviour that can continue into adult life [2], of note, the shaping of eating behaviours [3-5]. Parents and primary caregivers are key socioenvironmental drivers and influencers of childhood and adolescent behaviours, anxiety, self-esteem and selfefficacy around health and wellbeing [6-10]. The value of a parents' opinion, as a relationship of significance to adolescents, influences the quality of family relationships as well as their position as role models in their adolescent's life. However, Randal Day writes on family processes, 'the interaction in families is larger than any one person or even any one rule or pattern' [11, 12]. Therefore, although it is not possible to say that parents are the cause of an adolescent's eating problems, when the person who is their primary carer is criticising through body shaming, or worse, perceived to be rejecting them through likely misunderstandings in communication styles such as humour, teasing and jokes, the potential for adverse impact is worth considering as a possible influence or association [13-15]. Parental rejection is found to be positively associated with concurrent emotional eating [16] and related to psychological distress and anxiety in later adult life $[7,10,17]$. Such repeated emotional and behavioural experiences in adolescence may contribute to 'eating problems' in adulthood creating health, logistical, and fiscal burdens on the health system, the community, the individual and their family system [18]. Critically, this pathway has long-term sequelae including a substantially elevated risk of anxiety and depressive disorders, cardiovascular disease, chronic fatigue and chronic pain [10, 17, 19, 20].

The growing evidence lends itself to a simple stepped illustration: if you are underweight or overweight (clinically or not) in adolescence you are more likely to be teased by a mix of sources [20,21], with such teasing being positively related to anxiety $[10,17,22,23]$, and such anxiety directly affecting self-esteem $[10,23]$ and indirectly affecting eating through the use of 'unhealthy' or 'problem' eating behaviours as a coping mechanism. Therefore, this review will consider the prevalence of parental teasing, what parents teased about, the influence of parental teasing and any associations with eating disorders as an outcome. Even though the outcome of interest in this review is eating disorders, we will make note of psychological and psychosocial associations as significant predictors for unhealthy eating more generally in adolescence.

\section{Eating disorders, disordered eating and "eating} problems"

An Eating Disorder is a clinical categorisation that represents a grouping of eating-based behaviours that are deemed to differ from societal norms, including: anorexia nervosa, bulimia nervosa, binge eating disorder and other specified and unspecified eating disorders; these involve obesity, disturbed body image and / or weight loss behaviours [24]. The term disordered eating is typically used to allow a more expansive consideration of eating based problems that are broader than clinical diagnoses - for instance, "emotional eating" where overconsumption of food becomes a method of mood regulation [25] but which, in itself, is not cause for an eating disorder diagnosis. For this review, the term 'eating problems' is used as our outcome to encapsulate the diversity of terms used in the literature on parental teasing on weight, shape and or body and to cover both clinical and non-clinical descriptions of problematic eating behaviours in diverse samples of adolescents [9, 26-28].

\section{Family processes and communication}

Family processes consider the family as a system, a collection of interacting parts that are trying to attain a common goal and to achieve those communal aims, families are likely to repeat certain routines or patterns of behaviour; family processes consider all family members need to be fully subscribed to the goal for it to be achieved [11]. Previous research has considered family processes as a moderator for dietary behaviours [29] and influence for these family goals has previously been considered in light of the Tripartite Influence model [30]. Characteristics of family processes (such as family functioning, cohesion and conflicts), can contribute to an interplay between other characteristics (such as age, gender) and intrafamilial processes (such as parent-parent and parent-child relationships), and can influence associations and outcomes [29]. However, there have been dramatic shifts in the structure of families over the past few decades with increases in prevalence of single-parent and blended families, and the family structure is now extremely varied [31]. Family processes might also influence the way communication is heard in families. Krauss and Fussel, 1996 succinctly offer 'Communication is more than just talking, it is the process by which meaning is created and managed' [12]. Within families, this communication is complex (as is the family structure) and may be overt (obvious, explicit, observable and visible) or covert (more concealed, not obvious, more subtle and harder to read) [11, 32]. Adolescents, like parents, can sometimes decode messages incorrectly and messages may neither be sent nor received in the way they were intended [11]. 


\section{Teasing}

We specifically wanted to review the literature using 'teasing' as an intervention because it is a complex form of communication whose definition can vary between situations being used by a parent (our proposed context). Teasing is described as a specific type of bullying characterised by verbal taunts as a form of provocation (criticism or hostility) that is mitigated by off-record markers (playful gestures) - both of which may be present by varying degrees [33-35]. It requires the ability to understand intention, social context, non-verbal and non-literal communication [33, 34]. The level of emotional maturity required to process and contextualise this language is found in later childhood development and as such, the "humour" of teasing, as used by adults, may be comprehended by children in a far more literal and concrete manner. Furthermore, the impact of teasing can be cumulative, and teasing from multiple sources such as siblings and peers, or across a long period of time, puts children and subsequently, their adolescent self, at an even higher risk of more submissive behaviour, more unfavourable social comparisons and more emotional health problems [36$38]$ including eating problems $[39,40]$. Considered in the context of peer victimization, Hayden-Wade et al., [41] found teasing to be the most psychologically harmful of most communicative forms of bullying and harassment. Vandewalle et al., found that it was parental rejection, over peer rejection, that was found to be uniquely and positively associated with emotional eating [16] therefore, teasing specifically from parents is likely to be similarly detrimental and impactful and contribute to, not cause, the equifinality of eating problems.

Whilst a previous systematic review and meta-analysis of bullying and teasing associations with eating disorders has found those with eating disorders were significantly more likely to have been teased prior to the onset of their eating disorder, there were very few that considered the source of the teasing [42]. Therefore, to further our understanding of potential prevention strategies for families dealing with eating disorders and their onset in adolescents, it is valuable to consider 'teasing' as a particular form of communication from parents. Parental teasing in this review will focus on appearance or weight based/related teasing, hereafter referred to as A-RT and W-RT, unless a particular paper only studies weightbased teasing (W-BT), as well as any influence parental teasing has on other members of the household.

In this review we study adolescence defined by the World Health Organisation as between 10 and 19 years of age [1]. It is of particular interest as a stage of development synonymous with a higher prevalence of parentchild conflict [43] and it is a key period for establishing positive relationships with, and communications regarding, emotions and eating [4].

\section{Objective}

Whilst the impact of parental teasing on children under 10 years of age has been examined [44] there has not, to our knowledge, been a systematic synthesis of empirical findings to inform understanding of how parental teasing during, or continuing through, adolescence impacts on eating problems. Thus, this systematic review aimed to investigate the association between exposure to parental appearance related teasing (A-RT) and or weight related teasing (W-RT) and eating problems amongst adolescents.

\section{Method}

The review is reported using the PRISMA guidelines, [41]. A protocol was developed and established prior to conduct of the review registering a review question, a search strategy, inclusion and exclusion criteria, a risk of bias assessment, a plan for data extraction and a strategy for data synthesis. This strategy was prospectively registered on PROSPERO International Prospective Register of Systematic Reviews PROSPERO 2018 CRD42018109623 (https://www.crd.york.ac.uk/ PROSPERO/display_record.php? RecordID $=109,623$ ). Minor changes to the protocol and refining of the review question were made following the preliminary searches. This was because the preliminary searches generated a very high number of irrelevant results.

\section{Eligibility criteria and study selection}

Based on an understanding of previous research in the field of parental communication with adolescents and disordered eating, studies were included in this review if they included (i) a participant population of adolescents who were exposed to appearance or weight related teasing from parents, these two specific forms of teasing have validated measures such as the Perceptions of teasing scale (Thompson 1995) and Weight Based Victimization Questionnaire (Puhl et al., 2011) and were considered to offer a standardized reporting of parental teasing in relation to influences for disordered eating (ii) where the exposure to appearance or weight related teasing occurred during adolescence (aged between 10 and 19 years of age, the age the World Health Organisation define as adolescence). If a paper included participants outside the age range, for example 9 year or 20 years but these participants made up less than $10 \%$ of the sample and the mean age was within the selected age range these studies were to be included. If this was not clear the authors were to be contacted for confirmation and (iii) where the eating problems were identified as an outcome, via a validated instrument, or other assessment of weight, shape or body overvaluation or other body image cognitions such as the Eating Disorder Examination Questionnaire (Fairburn et al. 1994) or the Eating Disorder Inventory (Garner 1991). We inspected 
studies that included an observation of known psychopathology of eating disorders. However, if they did not specifically report eating disorders with a validated measure, those studies were not included in the final review. To increase sensitivity and capture as many studies as possible, both qualitative, quantitative, case studies and original full research studies were included in the original search. Although we did not set out to preclude Randomized Control Trials (RCTs), no RCT's were appropriate for inclusion. See Table 1.

\section{Information sources and search}

We used the PICO framework to consider adolescents' (population) appearance teasing (intervention) by parents (context) and associations with eating problems (outcome) [45]. The following electronic databases were searched based on research of appropriate databases for our area of interest: Ovid for Medline, EBSCOhost for CINAHL and APA PsycINFO, SCOPUS. Google returned results based on its own relevance algorithm, we search the first four pages (20 results per page) of Google Scholar for any other related articles. The first search considered a variety of search terms to establish our population (adolescents, teens, teenagers, youth); our intervention (teasing, bullying, verbal abuse, jokes, victimization); what the teasing was about (appearance, weight, shape, body); our context (parents, parental, maternal, paternal, mother, father); and outcome (eating disorder, eating problems, anorexia, bulimia, binge eating). We considered keyword and text searches to increase the likelihood of accurate results with adjustments made based on the protocols of each database. We manually searched reference lists for included studies, systematic reviews and meta-analyses that focused on teasing to increase sensitivity for parental teasing articles. No new articles were found [see Additional file 1 for a specific list of search terms used across each database]. The Boolean operator 'OR' was used to explode and map the Medical Subject Headings $(\mathrm{MeSH})$ terms. As an example, the specific search phrase we used for Scopus was ((TITLE-ABS-KEY (adolescen*) OR TITLE-ABS-KEY (teen*) OR TITLE-ABS KEY (youth*)) AND PUBYEAR > 1979) AND ((TITLE-ABS KEY (teasing) AND TITLE-ABS KEY (appearance OR body OR shape)) AND PUBYEAR > 1979) AND ((TITLE-ABS-KEY (parent*) OR TITLE-ABS-KEY (maternal) OR TITLE-ABS- KEY (paternal)) AND PUBYEAR > 1979) AND ((TITLE-ABS-KEY ("eating problems") OR TITLE-ABS-KEY (anorexia) OR TITLEABS-KEY (bulimia) OR TITLE-ABS-KEY ("eating problems")) AND PUBYEAR > 1979).

Subsequently these terms were then combined using the Boolean 'AND' operator. Finally, a year filter was applied to limit the returned articles to the time-period between 1980 and 2020. 1980 is when the Diagnostic and Statistical Manual of Mental Disorders, Third edition (DSM-III, 1952) first included Bulimia Nervosa and signified the modern era of eating disorders. To accommodate the researchers' language competencies the search was restricted to English and French language articles [see Table 1]. In an attempt to increase sensitivity, reference lists of included articles, prior systematic reviews

Table 1 Inclusion and Exclusion Criteria

\begin{tabular}{|c|c|c|}
\hline $\begin{array}{l}\text { Selection } \\
\text { Criteria }\end{array}$ & Inclusion Criteria & Exclusion Criteria \\
\hline Population & $\begin{array}{l}\text { Adolescents as defined by the World Health Organisation (WHO), between } 10 \\
\text { and } 19 \text { years of age. } \\
\text { Include teenagers, teens or youth. }\end{array}$ & $\begin{array}{l}\text { Non-related adolescent/teen/youth articles. } \\
\text { If the weight, shape, eating teasing happens outside } \\
\text { adolescence - younger than } 10 \text { or older than } 19 .\end{array}$ \\
\hline Intervention & $\begin{array}{l}\text { Teasing specific to appearance / weight / body image. } \\
\text { Appearance based teasing. } \\
\text { Weight based teasing. } \\
\text { Include verbal bullying. }\end{array}$ & $\begin{array}{l}\text { Article not specifically reporting teasing or verbal } \\
\text { bullying as a specific construct. } \\
\text { Not reporting appearance or weight-based teasing. }\end{array}$ \\
\hline Context & $\begin{array}{l}\text { Parents. } \\
\text { Include parental / mother / father. }\end{array}$ & $\begin{array}{l}\text { Article does not report specifically on parents. } \\
\text { If teasing was from peers, teachers, healthcare } \\
\text { workers, siblings. }\end{array}$ \\
\hline Outcome & $\begin{array}{l}\text { Disordered eating as an outcome or association. } \\
\text { Must include a validated measure of disordered eating. } \\
\text { Includes eating disorder psychopathology }\end{array}$ & $\begin{array}{l}\text { Article does not report disordered eating as an } \\
\text { outcome or association } \\
\text { Article does not include a standardized measure of } \\
\text { disordered eating. }\end{array}$ \\
\hline Study type & $\begin{array}{l}\text { Qualitative or Quantitative including case study designs, cross-sectional, longi- } \\
\text { tudinal and randomized control trials. Original Full Research Studies. }\end{array}$ & $\begin{array}{l}\text { Non-original studies, book reviews, opinion pieces, } \\
\text { non-peer reviewed journals, unpublished theses. }\end{array}$ \\
\hline Language & English and French Language Studies & Non-English or French language studies. \\
\hline Date range & $\begin{array}{l}\text { Studies from } 1980 \text { to present } \\
1980 \text { is when the Diagnostic and Statistical Manual of Mental Disorders, Third } \\
\text { edition (DSM-III, 1952) first included Bulimia Nervosa and signified the modern } \\
\text { era of eating disorders. }\end{array}$ & Being older that 1980. \\
\hline
\end{tabular}


and meta-analyses in this domain were manually screened for relevant studies. In the first stage, all article titles and abstracts were screened for relevant keywords, relevance to the specific research question and inclusion and exclusion criteria (LD). In the second stage two authors (LD and $\mathrm{PH}$ ) performed a full-text review of those remaining articles to confirm they met the eligibility criteria. If there was a disagreement about eligibility, these were to be resolved through discussion with a third reviewer (ST). A detailed list of records found by database [see Additional file 3] is mapped onto the PRISMA flow diagram [see Fig. 1]. We conducted this search within 24 months of completing the review and repeated the search in March and July 2020 to ensure a comprehensive literature search.
Risk of Bias in individual studies

The quality of the studies to be included in this review was assessed using the 16 items relevant to crosssectional studies from the Downs and Black Quality Index (DBQI) [46]. Items were scored 'Yes' [1] or 'No/ unable to determine' (0). They included a measure of the studies effectiveness in the following areas: nine questions pertaining to reporting, three questions pertaining to external validity, one question pertaining to internal validity and power each and two other questions related to our inclusion and exclusion criteria namely 'Was it an original study?; 'Did the study use a validated measure of disordered eating?'. The maximum score was 16 with higher scores indicating more robust methodology [see Additional file 2 for full Variation of Downs and Black

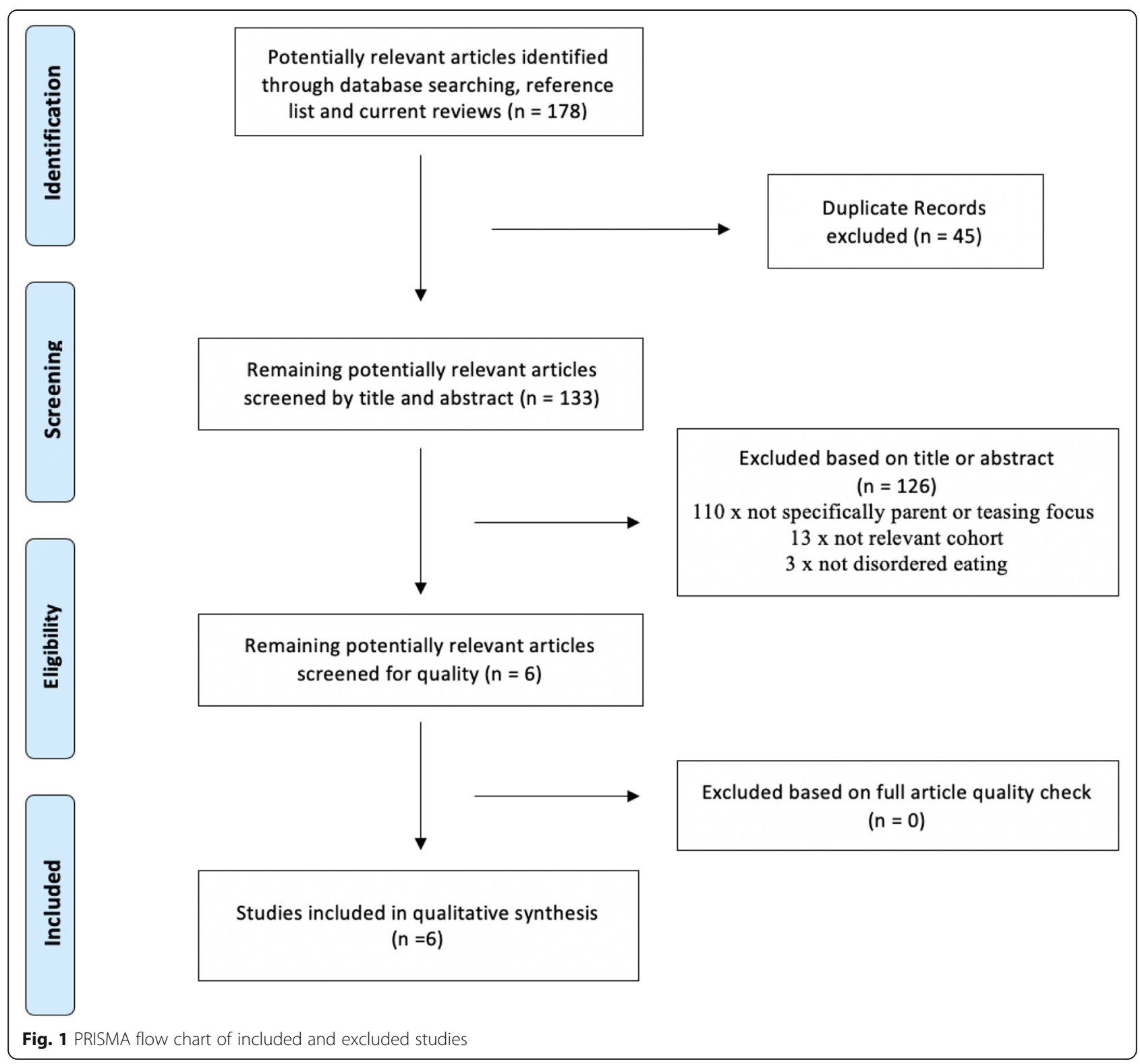


Checklist]. A sensitivity analysis was planned to test the impact of removing any potentially poor quality studies with a score $<10$ but this was not required.

\section{Results}

\section{Study selection}

As shown on Fig. 1, the initial database search yielded 178 records. 45 duplicates were identified and immediately excluded. Through title and abstract review, a further 126 records were then excluded.

Reasons for exclusion were decided in a systematic order, excluded because they were not specific to parent teasing as a construct (i.e. focused on family, sibling or peer teasing) or did not have a teasing focus, (i.e. weight commentary rather than teasing) $n=110$; excluded for not being from the cohort (i.e the cohort were younger than 10 years or older than 19 years) $n=13$; excluded for not measuring disordered eating $n=3$. Results of a hand-search of included paper, existing meta-analyses and systematic reviews resulted in no new articles but duplicates of the final included studies and duplicates of excluded papers. Full text articles were obtained for the remaining six records and a more detailed evaluation based on inclusion and exclusion criteria and quality assessment was undertaken by LD and $\mathrm{PH}$. There were no disagreements and all 6 remaining texts were included in the qualitative synthesis. Of the 178 studies originally identified, six studies met the criteria outlined for this systematic review. [see Additional File 3 for reference list for included articles].

The six studies included in this review displayed a Median of 15 using the DBQI measure with an interquartile range demonstrating the spread of the results between 14 and 15 . There was statistical ambiguity around the age of participants in one of the five studies, which suggested the inclusion of nine-year-old children in their cohort, therefore outside the inclusion criteria for this review which was specifically interested in the adolescent population due to the perceived increase in parental conflict at this age. The authors of the concerned paper [27] were contacted for clarification of age spread. The primary author responded and advised the included nine-year-olds represented less than $10 \%$ of the cohort. Based on this information, the study was retained in this review. All six included studies had low risk of bias with regards to describing the principle confounders in each group and using appropriate analyses for confounding [See Additional file 2 for full Variation of Downs and Black Checklist].

\section{Risk of bias across studies}

All six research papers included in this review were from peer-reviewed journals and were cross-sectional, with two including additional prospective data. All studies used non-clinical samples with two concentrating on minority populations. Four studies included mixed gendered populations, the balance focused on girls. Each study reported on funding sources and none were considered a conflict of interest or a source that could influence results presented in the studies. No studies used mixed methods and/or qualitative methodology.

\section{Study characteristics}

As shown in Table 2, the studies included in this review captured cohorts from America, Australia and Germany. One study was from a female only general population cohort [9]; two studies were mixed gender general population studies [26, 48]; one study was mixed gender population with binge-eating disorder (BED) and had a comparator group [47] another concentrated specifically on a Hispanic and African American demographic [27] and another study captured adolescent military dependents [28]. Of note, $91 \%$ of the adolescents in the review came from the single study [26]. Gender spread across studies was not equal with the total adolescents included in this review $(N=11,644)$ consisting of $59 \%$ girls $(n=$ $6887)$. Boys in the review equated to $41 \%(n=4757)$, with $95 \%$ of these male participants coming from the single study [26] study. The two papers that considered parent gender were both with a female only population $[9,27]$.

Across the studies, eating disorders were measured using the McKnight Risk Factor Survey [26, 27], the Eating Disorder Inventory subscales [9], Youth Risk Behaviour Survey [26] and Fairburn's 1993 Eating Disorder Examination V12 [28, 47], and Dutch Hilbert and Tuschen-Caffier 2016 variation [48]; Parental teasing was measured using the Perception of Teasing Scale [9, 47, 48], the Family-Weight Based Victimization Scale [28], and the McKnight Risk Factor Survey [26, 27]. One study additionally included specifically designed targeted teasing questions asking, "in the past year, how often has your mother made a comment about your weight or eating that made you feel bad?", the survey included the same question for fathers and responses ranged from "never" to "always" [26].

The statistical analyses across studies offer insight to the focus of each paper and a greater understanding of the results. Three papers did not focus on prevalence, therefore reported mean and standard deviation which made it harder to compare prevalence across studies in this review. Haines et al., [26] used generalized estimating equations and jointly modelled effects of the parental and family teasing on disordered eating variables using parental teasing as a socioenvironmental predictor variable. Webb et al., [48]. used multiple regression in their primary analysis and a regression model to test whether social adversity risk factors (self-reported teasing by 
Table 2 Characteristics of Included Studies

\begin{tabular}{|c|c|c|c|}
\hline Studies & Aims & Sample & Methodology \\
\hline $\begin{array}{l}\text { Authors } \\
\text { (Year) } \\
\text { (Country) }\end{array}$ & Specific to parent teasing & Number, Population, Mean Age & $\begin{array}{l}\text { Study style; Statistical analysis used; What } \\
\text { adjusted for; Specific teasing and eating } \\
\text { pathology and teasing measures. }\end{array}$ \\
\hline $\begin{array}{l}\text { Haines } \\
\text { et al. } \\
(2010) \\
{[26]} \\
\text { (USA) }\end{array}$ & $\begin{array}{l}\text { To identify shared risk and protective factors } \\
\text { for purging, binge eating and overweight. }\end{array}$ & $\begin{array}{l}10,540 \text { mixed gender ( } \mathrm{n}=6022 \\
\text { female) offspring of Nurses' Health } \\
\text { study (NHS II) and Growing Up Today } \\
\text { Study (GUTS) } \\
11-17 \text { years of age. } \\
\text { Female } M=13.9(S D=1.6) \text { Male } M=13.8 \\
(S D=1.5)\end{array}$ & $\begin{array}{l}\text { Cross Sectional Prospective design; Generalized } \\
\text { estimating equations; Weight-Related Teasing } \\
\text { (W-RT); Self-report questionnaires: Youth risk Be- } \\
\text { haviour Survey, McKnight Risk Factor Survey; } \\
\text { Self-report BMI. }\end{array}$ \\
\hline
\end{tabular}

Keery Evaluated prevalence and effect of teasing by 372 female American adolescents. et al. family members on body dissatisfaction, eating Non-clinical school population. (2005) [9] disturbance and psychological functioning. 11- 15 years of age. (USA)

Webb et al. (2020) [48] (Australia)
Olvera

et al. (2013)

[27]

(USA)

Pearlman et al. (2019) [28] (USA)

Pötzsch et al. (2018) [47]

(Germany)

Assessed association among parent and peer population of young adults.

Examined W-BT from parents and siblings in relation to disordered eating and psychosocial indices among adolescent military dependents at high risk for adult obesity and eating disorders.

Aimed to examine adolescents' perceived Weight teasing and perception of adolescent and maternal perspective of weight bias W-RT and disordered eating symptoms in a

141 female Hispanic and African American adolescents Healthy lifestyle / weight loss population. 9-14 years of age. $M=11.1 S D=1.5$ (10\%<9 years)

128 mixed gender Military dependents. 54\% female. 12-17 years of age $M=14.35$ years old, $S D=1.55$

90 mixed gender adolescents OW and BED $n=40, O W n=25, N W=$ 25

$78.9 \%$ female

$12-20$ years of age

OW \& BED - $M=14.58$ SD $=2.39$

$O W-M=14.53 S D=2.55$

$N W-M=15.84 S D=2.67$

Investigated change in emotional eating while also testing the influence of social-emotional risk factors.
379 mixed gender adolescents. $56 \%$ female $0-13$ years of age $M=12.0, S D=90$
Cross-sectional study; Regression Analysis; Appearance-related Teasing (A-RT); Self-report questionnaires: Perceptions of teasing scale weight-teasing frequency, The Eating Disorder Inventory - BD, The Eating Disorder Inventory DT, The Eating Disorder Inventory - B; Selfreport BMI.

Cross-sectional exploratory study; Regression Analysis; Weight-Related Teasing (W-RT); Selfreport questionnaires: Variation of McKnight Risk Factor Survey-IV; Practitioner measured BMI.

Cross-sectional study; Exploratory analysis of covariance; Weight-Based Teasing (W-BT); Selfreport questionnaires: Family Weight-Based Victimization Scale, Eating Disorder Examination interview; Self-report BMI.

Cross-sectional study; Weight-Based Teasing (WBT); self-report questionnaires: One item modified from Perception of Teasing Scale (POTS) with parents as source of teasing; Weight Bias Internalization scale (WBIS ) and the Eating Disorder Examination-Questionnaire (EDE-Q); attitudes Towards Obese Person Scale (ATOP); Beliefs About Obese Persons Scale (BAOP); Selfreport $\mathrm{BMI}$.

Cross Sectional Prospective design; multi-level modelling, and standard multiple regression; Appearance-related Teasing (A-RT); Weight Teasing Sub-scale of Perception of Teasing Scale (POTS) - with parents and peers as source of teasing; Dutch Eating Behavior Questionnaire (DEBQ), Mood and Feelings Questionnaire, Social Anxiety Scale for Children. Practitioner measured BMI.

$A-R T$ Appearance related teasing, $W-B T$ weight based teasing, $W-R T$, weight related teasing, $O W$ overweight, $B E D$ binge eating disorder, $N W$ normal weight

parents was one of the risk factors) were prospectively associated with emotional eating at T1 and T2 and presented similar patterns to Haines et al., modelling that girls receive more comments than boys overall. Pötzsch et al., [47] was the only study to include a comparator group. They used multivariate Analysis of Variance (MANOVA) to save power hypothesising group differences in stigmatizing variables including adolescents' perceived weight teasing. Keery et al., [9] used regression analysis with parental teasing treated as a continuous variable and hierarchical regression was used to predict the power of parental teasing. Olvera et al., [27] also used hierarchical regression analysis to determine weight related teasing using parent teasing as an independent variable and elements of disordered eating as dependent variables. Pearlman et al., [28] used exploratory analysis of covariance to assess for dependent disordered eating and psychosocial functioning outcome variables.

\section{Prevalence of parental teasing and gender}

Being able to appreciate prevalence in this field is a challenge because researchers are looking at prevalence of parental appearance or weight teasing from different constructs and via different perspectives, and therefore utilising different outcome measures resulting in the reporting of statistics that are not homogenous. Table 3 
Table 3 Prevalence of reported teasing by source

\begin{tabular}{|c|c|c|c|c|c|c|}
\hline \multirow[t]{2}{*}{ Study } & \multirow[t]{2}{*}{ No in sample } & \multicolumn{5}{|c|}{ Reported weight/ appearance teasing } \\
\hline & & Parents & Mother & Father & Siblings & Peers/classmates \\
\hline $\begin{array}{l}\text { Haines et al. } \\
\text { W-RT }\end{array}$ & $\begin{array}{l}N=10,540 \\
\text { Mixed Gender } \\
\text { At risk sample }\end{array}$ & $\begin{array}{l}\text { Can't work out actual \% } \\
\text { Girls } n=6022 M=1.3(S D=0.6) \\
\text { Boys } n=4518 M=1.2(S D=0.6)\end{array}$ & $\begin{array}{l}\text { Not } \\
\text { measured }\end{array}$ & $\begin{array}{l}\text { Not } \\
\text { measured }\end{array}$ & $\begin{array}{l}\text { Not } \\
\text { measured }\end{array}$ & Not measured \\
\hline $\begin{array}{l}\text { Keery et al. } \\
\text { A-RT }\end{array}$ & $\begin{array}{l}N=372 \\
\text { Girls only } \\
\text { General } \\
\text { Population }\end{array}$ & $23 \%$ & $13 \%$ & $19 \%$ & $29 \%$ & Not measured \\
\hline $\begin{array}{l}\text { Olvera et al. } \\
\text { W-RT }\end{array}$ & $\begin{array}{l}N=141 \\
\text { Girls only } \\
\text { Minority } \\
\text { Population }\end{array}$ & $42 \%$ & $46 \%$ & $39 \%$ & $\begin{array}{l}\text { Not } \\
\text { measured }\end{array}$ & $59 \%$ \\
\hline $\begin{array}{l}\text { Pearlman } \\
\text { et al. } \\
\text { W-BT }\end{array}$ & $\begin{array}{l}N=128 \\
\text { Mixed Gender } \\
\text { Minority } \\
\text { Population }\end{array}$ & $21.1 \%$ & $\begin{array}{l}\text { Not } \\
\text { measured }\end{array}$ & $\begin{array}{l}\text { Not } \\
\text { measured }\end{array}$ & $42.5 \%$ & No measured \\
\hline $\begin{array}{l}\text { Potzsch et al., } \\
\text { A-RT }\end{array}$ & $\begin{array}{l}N=90 \\
\text { Mixed gender } \\
\text { Comparison group } \\
\text { Girls } n=7178.9 \%\end{array}$ & $\begin{array}{l}\text { BED } n=40 M 7.68(S D 2.38) \\
\text { OW } n=25 M 6.40(S D 0.91) \\
\text { NW } n=25 M 6.08(S D 0.40)\end{array}$ & Not reported & Not reported & $\begin{array}{l}\text { Not } \\
\text { measured }\end{array}$ & Not measured \\
\hline $\begin{array}{l}\text { Webb et al., } \\
\text { A-RT }\end{array}$ & $\begin{array}{l}N=379 \\
\text { Girls } n=20756 \% \\
\text { Boys } n=17146 \% \\
\text { General } \\
\text { population }\end{array}$ & $\begin{array}{l}\text { Girls } n=207 M=1.58(S D= \\
0.89) \\
\text { Boys } n=171 M=1.41(S D= \\
0.80) \\
\text { Combined } M=1.50(S D=0.85)\end{array}$ & $\begin{array}{l}\text { Not } \\
\text { measured }\end{array}$ & $\begin{array}{l}\text { Not } \\
\text { measured }\end{array}$ & $\begin{array}{l}\text { Not } \\
\text { measured }\end{array}$ & $\begin{array}{l}\text { Girls } n=207 M=-0.08(S D= \\
0.87) \\
\text { Boys } n=171 M=-0.05(S D= \\
0.89) \\
\text { Combined } M=1.41 \quad(S D=0.46)\end{array}$ \\
\hline
\end{tabular}

represents the within studies reports of parental teasing which ranged between 21.1 and 42\%. Only two studies considered the gender of the parent $[9,27]$ yet without the same teasing focus. Pötzsch et al.'s, study did plan to consider the gender of the parent, but did not get sufficient fathers' responses $(n=5)$ [47]. Keery et al., was the only study to consider appearance specific teasing and parent gender, and found that $19 \%$ of girls reported ART by father and $13 \%$ reported A-RT by mother [9]. Conversely, Olvera et al.'s paper was the only one to consider parent gender and W-RT [27] and found the highest reported prevalence of all the studies (42\%) with $46 \%$ of weight teasing from mothers and 39\% from fathers. Pearlman et al.'s 2019 W-RT study [28] did not report parent gender but overall reported $21.1 \%$ of parents teased about weight and had limited analyses about parents as they combined parent teasing with sibling teasing and focused primarily on family weight based teasing (W-BT). The largest study by Haines et al., were contacted to ask to see if prevalence results exist but did not receive a reply by the time this paper was submitted.

Olvera et al., [27] reported more W-RT from their mothers than their fathers. Both Keery et al., [9] and Olvera et al., [27] considered the prevalence of teasing relevant to negative outcomes and found that the frequency of the teasing to be of significance. Keery et al., [9] reported higher teasing frequency was associated with poorer the outcomes. Olvera [27] also reported the girls in their study engaged with emotional eating and binge eating more as the frequency of the teasing increase.

\section{What parents teased about}

The studies reported weight-related teasing (W-RT) [26-28] and appearance-related teasing (A-RT) [9, 47, 49]. Four of the six included studies reported on binge eating [26-28, 47]. Half the studies reported on bulimia $[9,26,28], 33 \%$ reported on restriction $[9,28]$ and $50 \%$ $[27,48]$ reported on emotional eating. Contributing factors to eating disorders were also reported across the studies, internalization, social anxiety symptoms, depression, self-image, body dissatisfaction and weight and or shape concern.

\section{Influence of parental teasing}

Only two papers reported a potential influence on other family members [9, 28]. Keery et al., [9] reported girls teased by family members had significantly higher levels of negative outcomes than those with no family members that tease. Parental teasing, particularly paternal teasing, was found to significantly increase the frequency of sibling teasing, which in Keery et al., [9] and Pearlman et al.'s [28] studies reported sibling teasing was 42 and $29 \%$ respectively. Olvera et al., [27] found peer teasing to be slightly more prevalent at $59 \%$ than parental teasing (42\%). Keery et al., [9] found maternal teasing about weight and appearance increased risk of having a sibling who teases $(O R=1.37,95 \% C I=1.14-1.65)$. Yet, when 
paternal teasing was entered into the model, maternal teasing was no longer significant $(O R=1.15,95 \% C I=$ .93-1.42) and paternal teasing now increased risk of sibling teasing $(O R=1.4,95 \% C I=1.16-1.70)$. Neither Pötzsch et al., [47], nor Webb et al., [48] considered.

\section{Associated eating problems}

Keery et al.'s, female sample reported that both maternal and paternal A-RT was significantly associated with depression and paternal only A-RT was predictive of eating disorders (restriction, bulimic behaviours), and psychological outcomes (body dissatisfaction, body comparison, thin-ideal internalization and self-esteem) [9]. Similarly, Pötzsch et al. [47] found adolescents who perceived WRT significantly predicted global eating disorder psychopathology $F(1,82)=15.09, p<.001$ adj $R^{2}=0.16 ; b=$ $0.26, p=<.001,95 \%$ CI. This effect was significantly modified when considering an adolescent's level of weight bias internalization. Webb et al.'s, most recent 2020 study found Parental W-RT was associated with emotional eating $\mathrm{T} 1(\mathrm{M}=.22 p<.01)$ and increased over time $\mathrm{T} 2(\mathrm{M}=.27 \mathrm{p}<.01)$. In their prospective modelling one year later, self-reported appearance teasing by parents was one of two risk factors uniquely associated with emotional eating [48].

\section{Parent association with sibling teasing}

Olvera et al., [27] conducted hierarchical regressions on W-RT and, although exploratory, found W-RT by a parent was significantly associated with eating disorders (emotional eating and binge eating). Haines et al., [26] found parental W-RT was directly associated with binge eating for both boys (OR, 1.31; 95\% CI, 1.15-1.50) and girls (OR, 1.29; 95\%CI, 1.08-1.55) and overweight (OR, 1.64; $95 \% \mathrm{CI}, 1.36-1.96)$ in their cross-sectional results, yet only for girls in the prospective results. Pearlman et al., [28] found parental W-BT was significantly associated with lower self-esteem $(F(1,115)=8.81, p=0.02)$, and was associated with depression although they report did not reach significance $(F(1,116)=3.85, p=0.05)$.). For Pearlman, W-BT was not significantly associated with eating pathology.

\section{Discussion}

This is the first systematic review of the association between parents as a specific source of teasing and eating disorders. Our review showed that, previous research has indicated adolescents who experienced appearance or weight teasing from parents were more likely to have eating problems and other psychopathology which has been shown to contribute to eating problems. None of the research considers this teasing to be causative but part of the equifinality of eating problems.

\section{Prevalence of parental teasing and gender}

There are clear challenges in having discussions about appearance, weight, shape and even healthy eating without misunderstandings on what was being discussed and how it was being discussed. Parental communication is heard by the adolescent and then perceived either correctly or incorrectly as teasing, bullying or weight talk and then communicated to others in that light $[11,50]$. Prevalence of appearance teasing is complicated by these concerns between intention and perception. Pötzsch et al., [47] considered maternal attitudes and although results were not the focus of this review, it is important to consider, as the Tripartite Influence Model has illustrated, the influence of the parental modelling in our prevalence results [51]. All the included studies are influenced by this perception and were self-report although none of the papers discuss family processes, studies have considered the perception of the way words are heard and have suggested there are complexities to how words are intended and how they are received, the overt and the covert communication and the potential for misunderstanding within the context of family processes [11, 12, 31, 50]. However, our findings also confirm the importance of considering the source of teasing, particularly in the family home and beyond the collective family grouping [52]. Parents are a source of appearance and/or weight related teasing and, although not the most prevalent source, their influence is clearly noteworthy. There is a paucity of research considering the gender of the parent and as the studies included in this review illustrate, there are noteworthy risk factors for mothers and daughters which would benefit from further exploration in relation to family and intrafamilial processes $[9$, $26,27,31,47] .$. This is supported in broader research on parental and family comments that are not specific to teasing $[13,21,49,53]$.

\section{What parents teased about}

Our findings specifically considered weight and appearance teasing and were consistent with other research considering parent communication not specifically teasing. Weight-related teasing was more commonly associated with males, and fathers had higher prevalence with sons than daughters $[13,54,55]$. Our findings are consistent with the wider literature on parental teasing where several studies, mostly mixed gender, have reported that A-RT increased risk factors for eating disorders, such as thin idealisation, [13, 30, 49, 50, 53-55]. In particular, Keery et al., [9] found A-RT between fathers and daughters was associated with eating disorder psychopathology.

\section{Influence of parental teasing}

In line with previous research, our findings support the suggestion that having a parent who teased increased the 
risk of disordered eating directly $[9,26,27,47,48]$ as well as indirectly through the influence of their teasing on poor social functioning, negative self-evaluation and increased appearance sensitivity and anxiety over time $[9,16,28,55$, 56] and was considered highly influential to wellbeing outcomes $[9,26-28,47]$ regardless of it not being the most reported source. A further indirect influence from parental teasing was the permission effect for siblings to view their teasing as acceptable $[9,13,28,53,54]$. This is important as studies have found a high prevalence of peer teasing [27] and sibling $[9,28]$ with negative outcomes of increased eating disorder pathology.

\section{Association with eating disorders}

In terms of eating problems, we found binge eating, emotional eating, purging, restrictive eating through dieting and or skipping meals were associated with parental appearance or weight teasing, corroborates previous research an association with body dissatisfaction, disordered eating behaviours and unhealthy weight control behaviours [21, 36, 57-59]. However, none of the included studies sought to blame parents or to imply parents were directly responsible for disordered eating pathology.

With regards to gender and associations with eating disorders, Haines et al. [26] and Kerry et al.'s [9] findings are consistent with wider research that amongst girls that dieting $[60,61]$ and W-RT respectively were associated with an increased risk of disordered eating [62]. Amongst boys there were fewer risk factors that had a shared effect on weight related problems which is consistent with Neumark-Sztainer et al.'s findings [63].

In contrast Olvera et al., [27] found W-RT is related to be associated with only weight concern and eating problems (consistent with wider research [63] but not with dieting and skipping meals $[9,21,28,64]$. Possible explanations for this difference is the specific weight focused cohort and cultural differences between the samples.

Taken together, the findings reported here suggest parental conversations are important and may impact adolescent self-schema and therefore behaviour and coping strategies. None of the papers however examined parental intention or family processes and no causal conclusions can be drawn. Our findings are consistent with three meta-analyses conducted in this broad field of research [40, 42, 65]. One study by Menzel et al., [40] considered appearance-related teasing, body dissatisfaction, and disordered eating and support inclusion of intervention programs that focus on handling negative, appearance-related commentary. A second meta-analysis by Gillison et al., [65] did not focus on teasing but on weight commentary and equally supported the findings that encouraging positive parental communication around weight conversations is important. The third, a systematic review and meta-analysis specifically looked at bullying and teasing and associations with eating disorders and highlighted the importance of considering the source of the teasing. All authors call for more longitudinal research.

\section{Limitations and strengths}

A notable limitation of research identified in this review is that all studies included are cross sectional which limits the ability to investigate causal pathways. Every study $(N=6)$ used self-report questionnaires, which is both, a strength in terms of a resource efficient way to collect large amounts of measurable data, but a limitation due to the potential for reporting bias. All papers considered adolescent reports only which could be influenced by recall bias as well as by the quality of relationship with their parent which could influence how the words were received and none of the included studies considered the influence of family processes. Similarly, the self-reporting of BMI across most studies may also be considered fraught with reporting biases that might influence findings, however this is a common criticism of much general population research in eating problem studies and the findings are not substantially different in studies that used a practitioner to collect the BMI data. The lack of gender balance and the possible influence resulting from the inclusion of one large cohort study means future research should include gender comparisons. The lack of mixed-method and qualitative papers meant careful and in-depth investigations of the language, or discourse, itself was not well understood.

In addition to the limitations identified amongst the methodologies utilised by the studies captured in this review it is also pertinent to consider the limitations of the review process itself. For instance, the review focused very specifically on the word 'teasing' in relation to parents and this may have limited our ability to consider studies with other forms of communication such as healthful eating or this misunderstanding of parental humour and communication that could be taken as critical or influential by an adolescent. Although every effort was made to capture all literature in this field by hand searching relevant articles, our highly specific search phrase may have lost some sensitivity.

Strengths of the review include being able to consider French language papers; including grey literature and theses; contacting authors of papers that had an unclear number of participants outside our inclusion criteria for age; having multiple readers and agreeing on the quality and inclusion of $100 \%$ of the included papers.

In summary, the studies included in this review focused on parental appearance and weight-related teasing, and associations to eating problems in adolescents. This review found significant associations between parent 
appearance and weight teasing and eating disorders (binge eating, bulimia, emotional eating, weight control behaviours, restriction) and psychosocial contributors to eating disorders (self-esteem, depression, perfectionism, self-image, body dissatisfaction, weight concern, internalization and comparison). Notably, this was regardless of the intention by the parent and once again, emphasis must go on the purpose of this review to collate the existing data to see what further research is needed to better understand the influence of communication within the family processes. It is essential to establish the frequency and impact of inadvertent parental weight shape and or body teasing and what the consequences of this teasing could be on adolescents so support can be offered to parents on how to have healthful conversations around weight shape and eating. This synthesis of the findings offers parents more awareness around the words and humour used either directed at their children or around their children. The implications include consideration of the protective nature of healthful eating conversations and the risk of humour in parent and family health programs and in other public health measures to reduce the risk of eating and weight disorders. This is because, without adequate skills to understand the nuances of communication and humour from parents, adolescents may be more likely to find problem coping strategies which such as emotional eating or food restriction, and emotional avoidance strategies; the consequence of those problem coping strategies include appearance-rejection sensitivity, body dysmorphic disorder, disordered eating, emotional eating, binge eating, anorexia, and depression [17-19]. Furthermore, we know that healthy weight talk and supportive, positive parent-adolescent relationships have been considered protective for eating disorder pathology and protective against the potential negative impact of peer influences [66].

\section{Conclusion}

Every study included in this review considered parental teasing to be a concern, not only for the direct impacts but also the indirect as it may be associated with increased emotional health problems. Therefore, apportioning blame on parents is not the intention of this review and should not be for future studies. This review found that in research specific to parental appearance teasing there is a likely association with adolescent 'eating problems' however, there are limitations to the research to date. The impact of parental teasing is likely inadvertent and thereby responsive to change, therefore future research should employ representative longitudinal designs to develop a greater understanding of the direction of relationships between verbal and non-verbal communications, how and why they are perceived and dealt with by adolescents and consider the gendered source of the parental teasing within at family processes context. This review also echoes the call for a reduction in the acceptability of appearance and weight related teasing within family, the community and society at large.

\section{Abbreviations \\ WHO: World Health Organisation; A-RT: Appearance Related Teasing; W- \\ RT: Weight Related Teasing; W-BT: Weight Based Teasing; ED: Eating Disorder;} BE: Binge Eating; BMI: Body Mass Index; BDQI: Downs and Black Quality Index

\section{Supplementary Information}

The online version contains supplementary material available at https://doi. org/10.1186/s12889-021-10416-5.

Additional file 1. Search History by Database. A record of the search terms for each database

Additional file 2. Variation Downs and Black Checklist. This is the variation of the Downs and Black checklist used for analysis of included.

Additional file 3. Reference. Reference list of included articles

Acknowledgments

Not applicable.

\section{Authors' contributions}

Contributions to the design of the work: LMD, ST, NMVM, PH; Review of texts: LMD, PH; Contributed to revisions of the work: LMD, ST, NMVM, PH; Have approved the submitted version: LMD, ST, NMVM, PH; Have read and approved the manuscript: LMD, ST, NMVM, PH. Have agreed both to be personally accountable for the author's own contributions and to ensure that questions related to the accuracy or integrity of any part of the work, even ones in which the author was not personally involved, are appropriately investigated, resolved, and the resolution documented in the literature: LMD, ST, NMVM, PH

Funding

There was no research funding for this paper.

Availability of data and materials

All data included in this systematic review is from previously published papers. No new datasets were produced that have not been included in this journal submission.

\section{Declarations}

Ethics approval and consent to participate Not applicable.

Consent for publication

Not applicable.

\section{Competing interests}

Stephen Touyz (ST) has received royalties from Hogrefe and Huber, Mc Graw Hill Education and Routledge for the publication of books/chapters. He is the Chair of the Shire (Australian) BED Advisory Committee and has received travel grants, research grants and honoraria from Shire for commissioned reports. ST is a member of the Editorial Board of this journal. He is a consultant to Weight Watchers.

Phillipa Hay $(\mathrm{PH})$ has received in sessional fees and lecture fees from the Australian Medical Council, Therapeutic Guidelines publication, and New South Wales Institute of Psychiatry and royalties from Hogrefe and Huber, McGraw Hill Education, and Blackwell Scientific Publications, and she has received research grants from the NHMRC and ARC. She is Deputy Chair of the National Eating Disorders Collaboration in Australia (2012-2013). In July 2017 she provided a commissioned report for Shire Pharmaceuticals on 
lisdexamfetamine and binge eating disorder and in 2018 received honoraria for education of Psychiatrists.

\section{Author details}

${ }^{1}$ Translational Health Research Institute, Western Sydney University, Locked Bag 1797, Penrith, NSW 2751, Australia. ${ }^{2}$ Department of Psychology, University of Sydney, Sydney, Australia. ${ }^{3}$ School of Medicine, Western Sydney University, Penrith, Australia.

Received: 14 May 2020 Accepted: 9 February 2021

Published online: 06 March 2021

\section{References}

1. World Health Organization. Adolescent mental health [Internet]. World Health Organization; 2020 [updated 23 October 2019; cited 202010 January]. Available from: https://www.who.int/news-room/fact-sheets/deta il/adolescent-mental-health.

2. Dehghan M, Akhtar-Danesh N, Merchant AT. Childhood obesity, prevalence and prevention. Nutr J. 2005;4(1):24.

3. Golan M, Crow S. Parents are key players in the prevention and treatment of weight-related problems. Nutr Rev. 2004;62(1):39-50.

4. Blewitt C, Bergmeier H, Macdonald JA, Olsson CA, Skouteris H. Associations between parent-child relationship quality and obesogenic risk in adolescence: a systematic review of recent literature. Obes Rev. 2016;17(7): 612-22.

5. Duarte C, Pinto-Gouveia J, Rodrigues T. Being bullied and feeling ashamed: Implications for eating psychopathology and depression in adolescent girls. Journal of adolescence (London, England). 2015;44:259-68.

6. Berge J, Maclehose R, Loth K, Eisenberg M, Bucchianeri M, Neumark-Sztainer D. Parent conversations about healthful eating and weight: associations with adolescent disordered eating behaviors. Archives of Pediatrics \& Adolescent Medicine. 2013;167(8):746-53.

7. Bhutani R, Sudhir PM, Philip M. Teasing experiences, interpersonal sensitivity, self-schema and psychological distress in youth: an exploratory study. Psychol Stud. 2014;59(3):241-51.

8. Faught E, Vander Ploeg K, Chu YL, Storey K, Veugelers PJ. The influence of parental encouragement and caring about healthy eating on children's diet quality and body weights. Public Health Nutr. 2015;19(5):822-9.

9. Keery $H$, Boutelle $K$, van den Berg P, Thompson JK. The impact of appearance-related teasing by family members. J Adolesc Health. 2005;37(2): 120-7.

10. McCabe RE, Miller $J$, Laugesen N, Antony MM, Young L. The relationship between anxiety disorders in adults and recalled childhood teasing. Journal of Anxiety Disorders. 2010;24(2):238-43.

11. Day RD. Introduction to family processes: fifth edition. London: London: Routledge; 2010

12. Krauss RM, Fussell SR. Social psychological models of interpersonal communication. In: Higgins EE, Kruglanski A, editors. Social Psychology: Handbook of Basic Principles: Guilford; 1996. p. 655--701.

13. Schaefer MK, Salafia EHB. The connection of teasing by parents, siblings, and peers with girls' body dissatisfaction and boys' drive for muscularity: the role of social comparison as a mediator. Eat Behav. 2014;15(4):599-608.

14. Santoncini CU, Martin V, Garcia FJ, Gonzalez-Forteza C, Gutierrez BN. Disordered eating behavior and body weight and shape relatives' criticism in overweight and obese 15- to 19-year-old females. J Health Psychol. 2013;18(1):75-85.

15. Latzer $Y$, Stein $D$. A review of the psychological and familial perspectives of childhood obesity. J Eating Disord. 2013;1(1).

16. Vandewalle J, Moens E, Bosmans G, Braet C. The effect of parental rejection on the emotional eating behaviour of youngsters: a laboratory-based study. Appetite. 2017;108:219-25.

17. Mills P, Newman EF, Cossar J, Murray G. Emotional maltreatment and disordered eating in adolescents: testing the mediating role of emotion regulation. Child Abuse Negl. 2015;39:156-66.

18. Australia PWC. Weighing the cost of obesity: a case for action. 2015.

19. Martyn-Nemeth P, Penckofer S, Gulanick M, Velsor-Friedrich B, Bryant FB. The relationships among self-esteem, stress, coping, eating behavior, and depressive mood in adolescents. Research in Nursing \& Health. 2008;32(1): 96-109.

20. Eisenberg ME, Neumark-Sztainer D, Haines J, Wall M. Weight-teasing and emotional well-being in adolescents: longitudinal findings from project EAT. J Adolesc Health. 2006;38(6):675-83.
21. Neumark-Sztainer D, Falkner N, Story M, Perry C, Hannan PJ, Mulert S. Weight-teasing among adolescents: correlations with weight status and disordered eating behaviors. Int J Obes. 2002;26:123.

22. Haines J, Hannan P, van Den Berg P, Eisenberg M, Neumark-Sztainer D. Weight-related teasing from adolescence to Young adulthood: longitudinal and secular trends between 1999 and 2010. Obesity. 2013;21(9):E428-E34.

23. Ledley DR, Storch EA, Coles ME, Heimberg RG, Moser J, Bravata EA. The relationship between childhood teasing and later interpersonal functioning. J Psychopathol Behav Assess. 2006;28(1):33-40.

24. American Psychiatric Association. Diagnostic and statistical manual of mental disorders. 4th ed. Washington, DC: American Psychiatric Publishing Inc.; 2000.

25. Bodell LP, Pearson CM, Smith KE, Cao L, Crosby RD, Peterson CB, et al. Longitudinal associations between emotion regulation skills, negative affect, and eating disorder symptoms in a clinical sample of individuals with binge eating. Eat Behav. 2019;32:69-73.

26. Haines J, Kleinman KP, Rifas-Shiman SL, Field AE, Bryn AS. Examination of shared risk and protective factors for overweight and disordered eating among adolescents. Arch Pediatr Adolesc Med. 2010;164(4):336-43.

27. Olvera N, Dempsey A, Gonzalez E, Abrahamson C. Weight-related teasing, emotional eating, and weight control behaviors in Hispanic and African American girls. Eat Behav. 2013;14(4):513-7.

28. Pearlman AT, Schvey NA, Neyland MKH, Solomon S, Hennigan K, Schindler $\mathrm{R}$, et al. Associations between Family Weight-Based Teasing, Eating Pathology, and Psychosocial Functioning among Adolescent Military Dependents. International Journal of Environmental Research and Public Health. 2019;17(24).

29. Bjelland M, Hausken SES, Sleddens EFC, Andersen LF, Lie HC, Finset A, et al. Development of family and dietary habits questionnaires: the assessment of family processes, dietary habits and adolescents' impulsiveness in Norwegian adolescents and their parents. The international journal of behavioral nutrition and physical activity. 2014;11(1):130-

30. Webb HJ, Zimmer-Gembeck MJ, Waters AM, Farrell LJ, Nesdale D, Downey G. 'Pretty pressure' from peers, parents, and the media: a longitudinal study of appearance-based rejection sensitivity. J Res Adolesc. 2017;27(4):718-35.

31. Demuth S, Brown SL. Family structure, family processes, and adolescent delinquency: the significance of parental absence versus parental gender. The journal of research in crime and delinquency. 2016;41(1):58-81.

32. Watzlawick P. Change : principles of problem formation and problem resolution. [1st ed.] ed. Weakland JH, Fisch R, editors. New York: New York : Norton; 1974.

33. Heerey EA, Capps LM, Keltner D, Kring AM. Understanding teasing: lessons from children with autism. J Abnorm Child Psychol. 2005;33(1):55-68.

34. Keltner D, Capps L, Kring AM, Young RC, Heerey EA. Just teasing: a conceptual analysis and empirical review. Psychol Bull. 2001;127(2):229.

35. Storch EA, Roth DA, Coles ME, Heimberg RG, Bravata EA, Moser J. The measurement and impact of childhood teasing in a sample of young adults. Journal of Anxiety Disorders. 2004;18(5):681-94.

36. Eisenberg ME, Neumark-Sztainer D, Story M. Associations of weight-based teasing and emotional well-being among adolescents. Archives of Pediatrics \& Adolescent Medicine. 2003;157(8):733-8.

37. Troop NA, Allan S, Treasure JL, Katzman M. Social comparison and submissive behaviour in eating disorder patients. Psychology and psychotherapy. 2003;76(3):237-49.

38. Quick V, Byrd-Bredbenner C. Fatty, Fatty Two-by-Four: Weight Teasing History Is Associated with Disordered Eating Behaviors in Healthy Young Adult Women. American Dietetic Association Journal of the American Dietetic Association. 2010;110(9).

39. Fairburn CG, Doll HA, Welch SL, Hay PJ, Davies BA, O'Connor ME. Risk factors for binge eating disorder: a community-based, case-control study. Arch Gen Psychiatry. 1998;55(5):425-32.

40. Menzel JE, Schaefer LM, Burke NL, Mayhew LL, Brannick MT, Thompson JK Appearance-related teasing, body dissatisfaction, and disordered eating: a meta-analysis. Body Image. 2010;7(4):261-70.

41. Hayden-Wade HA, Stein RI, Ghaderi A, Saelens BE, Zabinski MF, Wilfley DE. Prevalence, characteristics, and correlates of teasing experiences among overweight children vs. non-overweight peers. Obesity research. 2005;13(8): 1381.

42. Lie $S \varnothing, R \varnothing \varnothing$, Bang L. Is bullying and teasing associated with eating disorders? A systematic review and meta-analysis. The International journal of eating disorders. 2019;52(5):497-514. 
43. Grotevant HD. Adolescent development in family contexts. Handbook of child psychology: Social, emotional, and personality development, Vol 3, 5th ed. Hoboken, NJ, US: John Wiley \& Sons Inc; 1998. p. 1097-149.

44. Ricciardelli LA, McCabe MP. Children's body image concerns and eating disturbance: a review of the literature. Clin Psychol Rev. 2001;21(3):325-44.

45. Stern C, Jordan Z, McArthur A. Developing the Review Question and Inclusion Criteria. AJN The American Journal of Nursing. 2014;114(4).

46. Downs $\mathrm{SH}$, Black N. The feasibility of creating a checklist for the assessment of the methodological quality both of randomised and non-randomised studies of health care interventions. Journal of Epidemiol Community Health. 1998;52(6):377-84.

47. Pötzsch A, Rudolph A, Schmidt R, Hilbert A. Two sides of weight bias in adolescent binge-eating disorder: adolescents' perceptions and maternal attitudes. Int J Eat Disord. 2018;51(12):1339-45.

48. Webb HJ, Kerin JL, Zimmer-Gembeck MJ. Increases in emotional eating during early adolescence and associations with appearance teasing by parents and peers, rejection, victimization, depression, and social anxiety. J Early Adolesc. 2020:27243162095046.

49. Densham K, Webb HJ, Zimmer-Gembeck MJ, Nesdale D, Downey G. Early adolescents' body dysmorphic symptoms as compensatory responses to parental appearance messages and appearance-based rejection sensitivity. Body Image. 2017;23:162-70.

50. Puhl RM, Himmelstein MS. A word to the wise: adolescent reactions to parental communication about weight. Child Obes. 2018;14(5):291-301.

51. Keery $H$, van den Berg $P$, Thompson JK. An evaluation of the tripartite influence model of body dissatisfaction and eating disturbance with adolescent girls. Body Image. 2004;1(3):237-51.

52. Loth K, Wall M, Choi CW, Bucchianeri M, Quick V, Larson N, et al. Family meals and disordered eating in adolescents: are the benefits the same for everyone? Int J Eat Disord. 2015;48(1):100-10.

53. Almenara CA, Jezek $\mathrm{S}$. The source and impact of appearance teasing: an examination by sex and weight status among early adolescents from the Czech Republic. The Journal of School Health. 2015;85(3):163-70.

54. Vincent M, McCabe M. Gender differences among adolescents in family, and peer influences on body dissatisfaction, weight loss, and binge eating behaviors. Journal of Youth and Adolescence. 2000:29(2):205-21.

55. Zimmer-Gembeck MJ, Webb HJ, Farrell LJ, Waters AM. Girls' and boys' trajectories of appearance anxiety from age 10 to 15 years are associated with earlier maturation and appearance-related teasing. Dev Psychopathol. 2018;30(1):337-50

56. Neumark-Sztainer D, Bauer KW, Friend S, Hannan PJ, Story M, Berge JM. Family weight talk and dieting: how much do they matter for body dissatisfaction and disordered eating behaviors in adolescent girls? J Adolesc Health. 2010;47(3):270-6.

57. Fulkerson JA, Strauss J, Neumark-Sztainer D, Story M, Boutelle K. Correlates of psychosocial well-being among overweight adolescents: the role of the family. Journal of Consulting \& Clinical Psychology. 2007;75(1):181-6.

58. Goldfield G, Moore C, Henderson K, Buchholz A, Obeid N, Flament M. The relation between weight-based teasing and psychological adjustment in adolescents. Paediatr Child Health. 2010;15(5):283.

59. Greenleaf C, Petrie TA, Martin SB. Relationship of weight-based teasing and Adolescents' psychological well-being and physical health. J Sch Health. 2014;84(1):49-55.

60. Neumark-Sztainer D, Wall M, Guo J, Story M, Haines J, Eisenberg M. Obesity, disordered eating, and eating disorders in a longitudinal study of adolescents: how do dieters fare 5 years later? J Am Diet Assoc. 2006;106(4): 559.

61. Stice E, Cameron RP, Killen JD, Hayward C, Taylor CB. Naturalistic weightreduction efforts prospectively predict growth in relative weight and onset of obesity among female adolescents. J Consult Clin Psychol. 1999;67(6):967.

62. Taylor CB, Bryson S, Doyle AAC, Luce KH, Cunning D, Abascal LB, et al. The adverse effect of negative comments about weight and shape from family and siblings on women at high risk for eating disorders. Pediatrics. 2006; 118(2):731-8

63. Neumark-Sztainer DR, Wall MM, Haines JI, Story MT, Sherwood NE, van den Berg PA. Shared Risk and Protective Factors for Overweight and Disordered Eating in Adolescents. American Journal of Preventive Medicine. 2007;33(5): 359-69.e3.

64. Haines J, Neumark-Sztainer D, Eisenberg ME, Hannan PJ. Weight teasing and disordered eating behaviors in adolescents: longitudinal findings from project EAT (eating among teens). Pediatrics. 2006;117(2):e209.
65. Gillison FB, Lorenc AB, Sleddens EFC, Williams SL, Atkinson L. Can it be harmful for parents to talk to their child about their weight? A metaanalysis Prev Med. 2016;93(C):135-46.

66. Laursen BP, Collins WA. Relationship pathways: from adolescence to Young adulthood. Thousand Oaks: Thousand Oaks: SAGE Publications; 2011.

\section{Publisher's Note}

Springer Nature remains neutral with regard to jurisdictional claims in published maps and institutional affiliations.
Ready to submit your research? Choose BMC and benefit from:

- fast, convenient online submission

- thorough peer review by experienced researchers in your field

- rapid publication on acceptance

- support for research data, including large and complex data types

- gold Open Access which fosters wider collaboration and increased citations

- maximum visibility for your research: over $100 \mathrm{M}$ website views per year

At BMC, research is always in progress.

Learn more biomedcentral.com/submissions 